Pacific Journal of Mathematics

PRODUCTS AND QUOTIENTS OF PROBABILISTIC METRIC
SPACES 


\title{
PRODUCTS AND QUOTIENTS OF PROBABILISTIC METRIC SPACES
}

\author{
Russell J. EGBERT

\begin{abstract}
In this paper some results concerning the products and quotients of probabilistic metric spaces are presented.
\end{abstract}

Probabilistic metric spaces were first introduced by K. Menger in 1942 and reconsidered by him in the early 1950's [3, 4, 5]. Since 1958, B. Schweizer and A. Sklar have been studying these spaces, and have developed their theory in depth $[9,10,11,12,13]$. These spaces have also been considered by several other authors [e. g., 2, 14, 15, 16]. An extensive, detailed up-to-date presentation may be found in [7].

In the sequel, we shall adopt the usual terminology, notation and conventions of the theory of probabilistic metric spaces, with but one exception: In all previous work, the distribution functions which determine the distances between points were required to have supremum one. Our investigations have led us to drop this requirement and the results which we present here show that doing so is natural. It is easy but tedious to check that the restriction to distribution functions with supremum one is not required in any of the previously established results which will be needed in the sequel.

In concluding this introduction we remark that products of probabilistic metric spaces have previously been considered by V. Istratescu and I. Vaduva [2]. However, their definition of Cartesian product employs associative functions which are stronger than Min, the strongest possible triangular norm. Because of this, and in view of the discussion given in [10], their results appear somewhat restrictive. Also, a number of the results concerning finite products, which are presented in $\S 1$ and which were announced in [1], have recently been obtained independently by A. Xavier [17].

\section{Product spaces.}

Definition 1. Let $\left(S_{1}, \widetilde{F}_{1}\right)$ and $\left(S_{2}, \widetilde{F}_{2}\right)$ be $P M$ spaces and let $T$ be a left-continuous $t$-norm. The T-product $\left(S_{1}, \widetilde{\mho}_{1}\right) \times\left(S_{2}, \widetilde{F}_{2}\right)$ of $\left(S_{1}, \widetilde{\mho}_{1}\right)$ and $\left(S_{2}, \widetilde{F}_{2}\right)$ is the space $\left(S_{1} \times S_{2}, T\left(\widetilde{F}_{1}, \widetilde{F}_{2}\right)\right)$, where $S_{1} \times S_{2}$ is the Cartesian product of the sets $S_{1}$ and $S_{2}$ and $T\left(\widetilde{\digamma}_{1}, \widetilde{F}_{2}\right)$ is the mapping from $\left(S_{1} \times S_{2}\right) \times\left(S_{1} \times S_{2}\right)$ into the set of distribution functions $A$ given by 


$$
T\left(\Im_{1}, \mathfrak{F}_{2}\right)(p, q)=T\left(\mathfrak{\Im}_{1}\left(p_{1}, q_{1}\right), \widetilde{\mho}_{2}\left(p_{2}, q_{2}\right)\right),
$$

for any $p=\left(p_{1}, p_{2}\right)$ and $q=\left(q_{1}, q_{2}\right)$ in $S_{1} \times S_{2}$.

We shall often denote $S_{1} \times S_{2}$ by $S$ and $T\left(\mathfrak{\mho}_{1}, \mathfrak{\mho}_{2}\right)$ by $\mathfrak{\mho}_{T}$, and when there can be no doubt, omit the reference to $T$ and write $\Im_{T}(p, q)=F_{p q}$.

As immediate consequences of Definition 1 we have:

TheOREM 1. The T-product $\left(S, \mathfrak{\mho}_{T}\right)$ of two PM spaces $\left(S_{1}, \mathfrak{\mho}_{1}\right)$ and $\left(S_{2}, \widetilde{\mho}_{2}\right)$ is a $P M$ space.

Theorem 2. If $\left(S_{1}, \mathfrak{\mho}_{1}, T\right)$ and $\left(S_{2}, \mathfrak{\mho}_{2}, T\right)$ are Menger spaces under the same left-continuous t-norm $T$, then their T-product is a Menger space under $T$.

CoRollary 1. If $\left(S_{1}, \widetilde{\mho}_{1}, T_{1}\right)$ and $\left(S_{2}, \widetilde{\mho}_{2}, T_{2}\right)$ are Menger spaces and if there exists a left-continuous t-norm $T$ which is weaker than $T_{1}$ and $T_{2}$, then their T-product is a Menger space under $T$.

We now determine conditions under which the product of equilateral, simple, or $\alpha$-simple $P M$ spaces is again a $P M$ space of the same type. We begin with,

THEOREM 3. If $\left(S_{1}, \mathfrak{F}_{1}\right)$ and $\left(S_{2}, \mathfrak{F}_{2}\right)$ are equilateral spaces generated by the same distribution function $G$, then their Min product $\left(S_{1} \times S_{2}, \mathfrak{F}_{\text {Min }}\right)$ is an equilateral space generated by $G$.

Proof. Let $p=\left(p_{1}, p_{2}\right)$ and $q=\left(q_{1}, q_{2}\right)$ be distinct points in $S_{1} \times S_{2}$ and consider

$$
F_{p q}(x)=\operatorname{Min}\left(F_{p_{1} q_{1}}(x), F_{p_{2} q_{2}}(x)\right) \text {. }
$$

In all three cases, (1) $p_{1} \neq q_{1}, p_{2} \neq q_{2}$; (2) $p_{1}=q_{1}, p_{2} \neq q_{2}$; (3) $p_{1} \neq q_{1}$, $p_{2}=q_{2}$, we have $F_{p q}(x)=G(x)$ from which the result follows.

It should be noted that the choice of Min in the above theorem is necessary, since we must have

$$
T(H(x), G(x))=T(G(x), G(x))=G(x),
$$

where $H$ is the distribution function defined by

$$
H(x)=\left\{\begin{array}{l}
0, x \leqq 0 \\
1, x>0
\end{array}\right.
$$

In general, this is true only for $T=$ Min. Similarly, it is necessary that $\left(S_{1}, \widetilde{\mho}_{1}\right)$ and $\left(S_{2}, \widetilde{F}_{2}\right)$ be generated by the same distribution function. 
THEOREM 4. If $\left(S_{1}, \mathfrak{\mho}_{1}\right)$ and $\left(S_{2}, \mathfrak{\mho}_{2}\right)$ are simple spaces generated by the metric spaces $\left(S_{1}, d_{1}\right)$ and $\left(S_{2}, d_{2}\right)$, respectively, and the same distribution function $G$, then their Min-product $\left(S_{1} \times S_{2}, \mathfrak{F}_{\text {Min }}\right)$ is a simple space generated by the metric space $\left(S_{1} \times S_{2}, \operatorname{Max}\left(d_{1}, d_{2}\right)\right)$ and $G$.

Proof. Let $p=\left(p_{1}, p_{2}\right)$ and $q=\left(q_{1}, q_{2}\right)$ belong to $S_{1} \times S_{2}$. It follows from Theorem 1 that $F_{p q}=H$ if and only if $p=q$. Thus we have only to show that whenever $p \neq q F_{p q}(x)=G(x / d(p, q))$, where $d(p, q)=\operatorname{Max}\left(d_{1}\left(p_{1}, q_{1}\right), d_{2}\left(p_{2}, q_{2}\right)\right)$. There are again three cases to consider:

(1) If $p_{1} \neq q_{1}$ and $p_{2} \neq q_{2}$, then

$$
\begin{aligned}
F_{p q}(x) & =\operatorname{Min}\left\{G\left(x / d_{1}\left(p_{1}, q_{1}\right)\right), G\left(x / d_{2}\left(p_{2}, q_{2}\right)\right)\right\} \\
& =G\left(x / \operatorname{Max}\left(d_{1}\left(p_{1}, q_{1}\right), d_{2}\left(p_{2}, q_{2}\right)\right)\right)=G(x / d(p, q)) .
\end{aligned}
$$

(2) If $p_{1}=q_{1}$ and $p_{2} \neq q_{2}$, then $d_{1}\left(p_{1}, q_{1}\right)=0$ and

$$
\begin{aligned}
F_{p q}(x) & =\operatorname{Min}\left(H(x), G\left(x / d_{2}\left(p_{2}, q_{2}\right)\right)=G\left(x / d_{2}\left(p_{2}, q_{2}\right)\right)\right. \\
& =G\left(x / \operatorname{Max}\left(0, d_{2}\left(p_{2}, q_{2}\right)\right)\right)=G(x / d(p, q)) .
\end{aligned}
$$

(3) If $p_{1} \neq q_{1}$ and $p_{2}=q_{2}$, we proceed as in (2) above.

Definition 2. A distance distribution function $G$ is strict if it is continuous and strictly increasing on $[0, \infty)$ and with $\operatorname{Sup}_{x} G(x)=1$.

The restriction of $G$ to $[0, \infty)$ has an inverse which we will denote by $G^{*}$ and refer to as the inverse of $G$.

TheoRem 5. Let $\left(S_{1}, \mathfrak{F}_{1}\right)$ and $\left(S_{2}, \widetilde{\mho}_{2}\right)$ be $\alpha$-simple spaces, $\alpha \geqq 1$, generated by the metric spaces $\left(S_{1}, d_{1}\right)$ and $\left(S_{2}, d_{2}\right)$, respectively, and the same strict distribution function $G$. Let $T$ be the strict t-norm whose additive generator is $\left(G^{*}\right)^{-m / \alpha}$, where $m \geqq 1[12]$. Then the $T$-product $\left(S_{1} \times S_{2}, \mathfrak{\Im}_{T}\right)$ is an $\alpha$-simple space generated by the metric space $\left(S_{1} \times S_{2},\left(d_{1}^{m}+d_{2}^{m}\right)^{1 / m}\right)$ and $G$.

Proof. Let $d=\left(d_{1}^{m}+d_{2}^{m}\right)^{1 / m}$ and let $p=\left(p_{1}, p_{2}\right)$ and $q=\left(q_{1}, q_{2}\right)$ be distinct points of $S_{1} \times S_{2}$. We have to show that

$$
F_{p q}(x)=G\left(x / d^{\alpha}(p, q)\right) \text {. }
$$

We again split cases:

(1) If $p_{1} \neq q_{1}$ and $p_{2} \neq q_{2}$, then

$$
\begin{aligned}
F_{p q}(x) & =T\left(G\left(x / d_{1}^{\alpha}\left(p_{1}, q_{1}\right)\right), G\left(x / d_{2}^{\alpha}\left(p_{2}, q_{2}\right)\right)\right) \\
& =f^{*}\left\{f G\left(x / d_{1}^{\alpha}\left(p_{1}, q_{1}\right)\right)+f G\left(x / d_{2}^{\alpha}\left(p_{2}, q_{2}\right)\right)\right\},
\end{aligned}
$$


where $f=\left(G^{*}\right)^{-m / \alpha}$ and $f^{*}=G\left(j^{-\alpha / m}\right)$ and $j$ denotes the identity function. It follows that $f G=j^{-m / \alpha}$, whence

$$
\begin{aligned}
F_{p q}(x) & =f^{*}\left\{x^{-m / \alpha}\left(d_{1}^{m}\left(p_{1}, q_{1}\right)+d_{2}^{m}\left(p_{2}, q_{2}\right)\right)\right\} \\
& =G\left\{x\left(d_{1}^{m}\left(p_{1}, q_{1}\right)+d_{2}^{m}\left(p_{2}, q_{2}\right)\right)^{-\alpha / m}\right\}=G\left(x / d^{\alpha}(p, q)\right) .
\end{aligned}
$$

(2) If $p_{1}=q_{1}$ and $p_{2} \neq q_{2}$, then for $x>0$

$$
F_{p q}(x)=T\left(H(x), G\left(x / d_{2}^{\alpha}\left(p_{2}, q_{2}\right)\right)\right)=G\left(x / d^{\alpha}(p, q)\right) .
$$

(3) If $p_{1} \neq q_{1}$ and $p_{2}=q_{2}$, we proceed as in (2).

As a result of Theorem 2 in [12] it follows that for $\alpha>1$ the $\alpha$-simple spaces above are all Menger spaces under the $t$-norm $T^{\prime}$ whose additive generator is $\left(G^{*}\right)^{1 /(1-\alpha)}$. Moreover as B. Schweizer has observed, if we want to have $T=T^{\prime}$, then $\alpha$ and $m$ must satisfy the equation $1 /(1-\alpha)=-m / \alpha$, from which it follows that

$$
1 / \alpha+1 / m=1 \text {. }
$$

We now turn to the question of topologies on the $T$-product spaces and state as our final result of this section.

THEOREM 6. Let $\left(S_{1}, \widetilde{\mho}_{1} T\right)$ and $\left(S_{2}, \widetilde{\mho}_{2} T\right)$ be Menger spaces under the same left-continuous $t$-norm. Let $\mathfrak{B}^{\prime}$ denote the $\varepsilon-\lambda$ neighborhood system in $\left(S_{1} \times S_{2}, \mathfrak{\mho}_{T}, T\right)$ and let $\mathfrak{B}$ denote the neighborhood system in $\left(S_{1} \times S_{2}, \mathfrak{F}_{T}, T\right)$ consisting of the Cartesian products $N_{p_{1}} \times N_{p_{2}}$, where $N_{p_{1}}$ and $N_{p_{2}}$ are $\varepsilon-\lambda$ neighborhoods in the respective component spaces $\left(S_{1}, \mathfrak{F}_{1}, T\right)$ and $\left(S_{2}, \mathfrak{F}_{2}, T\right)$. Then $\mathfrak{B}$ and $\mathfrak{B}^{\prime}$ induce equivalent topologies on $\left(S_{1} \times S_{2}, \widetilde{\mho}_{T}, T\right)$.

Proof. We first note that since $T$ is assumed to be left-continuous, the neighborhood systems $\mathfrak{B}$ and $\mathfrak{B}^{\prime}$ are in fact bases for their respective topologies [10]. Consequently, it suffices to show that for each $B$ in $\mathfrak{B}$ there exists a $B^{\prime}$ in $\mathfrak{B}^{\prime}$ such that $B^{\prime} \subseteq B$, and conversely. Let $A_{1} \times A_{2}$ be an element of $\mathfrak{B}$. Then there exist neighborhoods $N_{p_{1}}\left(\varepsilon_{1}, \lambda_{1}\right)$ and $N_{p_{2}}\left(\varepsilon_{2}, \lambda_{2}\right)$ contained in $A_{1}$ and $A_{2}$, respectively. Let

$$
\varepsilon=\operatorname{Min}\left(\varepsilon_{1}, \varepsilon_{2}\right), \lambda=\operatorname{Min}\left(\lambda_{1}, \lambda_{2}\right)
$$

and $p=\left(p_{1}, p_{2}\right)$. We will show that $N_{p}(\varepsilon, \lambda) \subseteq A_{1} \times A_{2}$. To this end, let $q=\left(q_{1}, q_{2}\right)$ belong to $N_{p}(\varepsilon, \lambda)$. Then we have

$$
\begin{aligned}
F_{p_{1} q_{1}}\left(\varepsilon_{1}\right) & =T\left(F_{p_{1} q_{1}}\left(\varepsilon_{1}\right), 1\right) \geqq T\left(F_{p_{1} q_{1}}\left(\varepsilon_{1}\right), F_{p_{2} q_{2}}\left(\varepsilon_{2}\right)\right) \\
& \geqq T\left(F_{p_{1} q_{1}}(\varepsilon), F_{p_{2} q_{2}}(\varepsilon)\right)=F_{p q}(\varepsilon)>1-\lambda \geqq 1-\lambda_{1} .
\end{aligned}
$$

Similarly, $F_{p_{2} q_{2}}\left(\varepsilon_{2}\right)>1-\lambda_{2}$. Thus $q_{1} \in N_{p_{1}}\left(\varepsilon_{1}, \lambda_{1}\right)$ and $q_{2} \varepsilon N_{p_{2}}\left(\varepsilon_{2}, \lambda_{2}\right)$, from which the result follows. 
Conversely, suppose that $N_{p}(\varepsilon, \lambda)$ is an element of $\mathfrak{B}$. Since $T$ is left-continuous, $\operatorname{Sup}_{x<1} T(x, x)=1$, so that there exists an $\eta$ such that

$$
T(1-\eta, 1-\eta)>1-\lambda
$$

Let $q=\left(q_{1}, q_{2}\right)$ belong to $N_{p_{1}}(\varepsilon, \eta) \times N_{p_{2}}(\varepsilon, \eta)$. Then

$$
F_{p q}(\varepsilon)=T\left(F_{p_{1} q_{1}}(\varepsilon), F_{p_{2} q_{2}}(\varepsilon)\right) \geqq T(1-\eta, 1-\eta)>1-\lambda
$$

so that $q \in N_{p}(\varepsilon, \lambda)$ and $N_{p_{1}}(\varepsilon, \eta) \times N_{p_{2}}(\varepsilon, \eta) \cong N_{p}(\varepsilon, \lambda)$. This completes the proof.

Note that the proof of the first half of Theorem 6, i.e., of the fact that for any $B$ in $\mathfrak{B}$ there exists a $B^{\prime}$ in $\mathfrak{O}^{\prime}$ such that $B^{\prime} \cong B$, is independent of any hypothesis on the $t$-norm $T$, while the proof of the second half requires only that $\operatorname{Sup}_{x<1} T(x, x)=1$.

We conclude this section by remarking that all the above results may be extended in an obvious way to include products of any finite number of $P M$ spaces.

2. Diameter of and distance between sets. Throughout this section $(S, \mathscr{F}, T)$ will denote a Menger space with a continuous $t$-norm.

Definition 3. Let $A$ be a nonempty subset of $S$. The function $D_{A}$, defined by

$$
D_{A}(x)=\operatorname{Sup}_{t<x}\left[\operatorname{Inf}_{p, q \in A} F_{p q}(t)\right],
$$

will be called the probabilistic diameter of $A$.

We now establish the properties of the probabilistic diameter. Proofs requiring only routine calculations will be omitted.

Theorem 7. The function $D_{A}$ is a distribution function.

Definition 4. A nonempty subset $A$ of $S$ is bounded if $\operatorname{Sup}_{x} D_{A}(x)=1$, semi-bounded if $0<\operatorname{Sup} D_{A}(x)<1$, and unbounded if $\mathrm{D}_{A}=0$.

Theorem 8. If $A$ is a nonempty subset of $S$, then $D_{A}=H$ if and only if $A$ consists of a single point.

Theorem 9. If $A$ and $B$ are nonempty subsets of $S$ and $A \subseteq B$, then $D_{A} \geqq D_{B}$.

THeorem 10. If $A$ and $B$ are two nonempty subsets of $S$ such that $A \cap B=\varnothing$, then 


$$
D_{A \cup B}(x+y) \geqq T\left(D_{A}(x), D_{B}(y)\right) \text {. }
$$

Proof. Let $x$ and $y$ be given. To establish (2.1) we first show that

$$
\operatorname{Inf}_{p, q \in A \cup B} F_{p q}(x+y) \geqq T\left(\operatorname{Inf}_{p, q \in A} F_{p q}(x), \operatorname{Inf}_{p, q \in B} F_{p q}(y)\right) .
$$

There are two distinct cases to consider:

Case (1).

$$
\operatorname{Inf}_{p, q \in A \cup B} F_{p q}(x+y)=\operatorname{Inf}_{\substack{p \in A \\ q \in B}} F_{p q}(x+y) .
$$

Now for any triple of points $p, q$ and $r$ in $S$, we have

$$
F_{p q}(x+y) \geqq T\left(F_{p r}(x), F_{r q}(y)\right) .
$$

Taking the infinum of both sides of this inequality as $p$ ranges over $A, q$ ranges over $B$ and $r$ ranges over $A \cap B$, and using (2.3) we have,

$$
\operatorname{Inf}_{p, q \in A \cup B} F_{p q}(x+y) \geqq \operatorname{Inf}_{\substack{p \in A \\ q \in B \\ r \in A \cap B}} T\left(F_{p r}(x), F_{r q}(y)\right) .
$$

However, since $T$ is continuous and nondecreasing we obtain

$$
\operatorname{Inf}_{p, q \in A \cup B} F_{p q}(x+y) \geqq T\left(\operatorname{Inf}_{p, r \in A} F_{p r}(x), \operatorname{Inf}_{r, q \in B} F_{r q}(y)\right) .
$$

Case (2).

$$
\operatorname{Inf}_{p, q \in A \cup B} F_{p q}(x+y)<\operatorname{Inf}_{\substack{p \in A \\ q \in B}} F_{p q}(x+y) .
$$

In this case one of the equalities,

$$
\operatorname{Inf}_{p, q \in A \cup B} F_{p q}(x+y)=\operatorname{Inf}_{p, q \in A} F_{p q}(x+y)
$$

or

$$
\operatorname{Inf}_{p, q \in A \cup B} F_{p q}(x+y)=\operatorname{Inf}_{p, q \in B} F_{p q}(x+y)
$$

must hold. If the first equality holds, we have

$$
\begin{aligned}
\operatorname{Inf}_{p, q \in A \cup B} F_{p q}(x+y) & \geqq T\left(\operatorname{Inf}_{p, q \in A} F_{p q}(x), H(y)\right) \\
& \geqq T\left(\operatorname{Inf}_{p, q \in A} F_{p q}(x), \operatorname{Inf}_{p, q \in B} F_{p q}(y)\right) .
\end{aligned}
$$


The same argument works for the second equality. This establishes (2.2).

Finally, using the fact that the rectangle

$$
\{(s, t): 0 \leqq s \leqq x, 0 \leqq t \leqq y\}
$$

is contained in the triangle $\{(s, t): s, t \geqq 0, s+t<x+y\}$, the inequality (2.2) and the continuity of $T$ we have

$$
\begin{aligned}
D_{A \cup B}(x+y) & =\operatorname{Sup}_{s+t<x+y}\left[\operatorname{Inf}_{p, q \in A \cup B} F_{p q}(s+t)\right] \\
& \geqq \operatorname{Sup}_{\substack{s<x \\
t<y}}\left[\operatorname{Inf}_{p, q \in A \cup B} F_{p q}(s+t)\right] \\
& \geqq T\left(\operatorname{Sup}_{s<x}\left[\operatorname{Inf}_{p, q \in A} F_{p q}(s)\right], \operatorname{Sup}_{t<y}\left[\operatorname{Inf}_{p, q \in B} F_{p q}(t)\right]\right) \\
& =T\left(D_{A}(x), D_{B}(y)\right) .
\end{aligned}
$$

Theorem 11. If $A$ is a nonempty subset of $S$, then $D_{A}=D_{\bar{A}}$, where $\bar{A}$ denotes the closure of $A$ in the $\varepsilon-\lambda$ topology on $S$ [10].

Proof. Since $A \subseteq \bar{A}$, it follows from Theorem 7 that $D_{A} \geqq D_{\bar{A}}$.

Let $\eta>0$ be given. In view of the uniform continuity of $\widetilde{F}$ with respect to the Lévy metric $L$ on $\Delta[8]$ there exists an $\varepsilon>0$ and a $\lambda>0$ such that for any four points $p_{1}, p_{2}, p_{3}$ and $p_{1}$ in $S$,

$$
L\left(F_{p_{1} p_{2}}, F_{p_{3} p_{4}}\right)<\eta
$$

whenever $F_{p_{1} p_{3}}(\varepsilon)>1-\lambda$ and $F_{p_{2} p_{4}}(\varepsilon)>1-\lambda$.

Next, with each point $\bar{p}$ in $\bar{A}$ associate a point $p(\bar{p})$ in $\bar{A}$ such that $F_{p}(\bar{p})-\bar{p}(\varepsilon)>1-\lambda$. Then, in view of the above for any pair of points $\bar{p}$ and $\bar{q}$ in $A$,

$$
L\left(F_{p(\bar{p}) q(\bar{q})}, F_{\bar{p} \bar{q}}\right)<\eta .
$$

In particular, for all $t$ we have,

$$
F_{p(\bar{p}) q(\bar{q})}(t-\eta)-\eta \leqq F_{\bar{p} \bar{q}}(t) .
$$

Let $A_{\eta}=\{p(\bar{p}): \bar{p} \in \bar{A})$. Then since $A_{\eta} \subseteq A$,

$$
\begin{aligned}
\operatorname{Inf}_{\bar{p}, \bar{q} \in \bar{A}} F_{\bar{p} \bar{q}}(t) & \geqq \operatorname{Inf}_{\bar{p}, \bar{q} \in \bar{A}} p(\bar{p}) q(\bar{q})(t-\eta)-\eta \\
& =\operatorname{Inf}_{p, q \in A \eta} F_{p q}(t-\eta)-\eta \geqq \operatorname{Inf}_{p, q \in A} F_{p q}(t-\eta)-\eta .
\end{aligned}
$$

Now, taking the supremum for $t<x$ of the above inequality yields 


$$
\begin{aligned}
D_{\bar{A}}(x) & =\operatorname{Sup}_{t<x}\left[\operatorname{Inf}_{\bar{p}, \bar{q} \in \bar{A}} F_{\bar{p} \bar{q}}(t)\right] \geqq \operatorname{Sup}_{t>x}\left[\operatorname{Inf}_{p, q \in A} F_{p q}(t-\eta)\right]-\eta \\
& =\operatorname{Sup}_{t<x-\eta}\left[\operatorname{Inf}_{p, q \in A} F_{p q}(t)\right]-\eta=D_{A}(x-\eta)-\eta .
\end{aligned}
$$

Since the above inequality is valid for all $\eta$ and since $D_{A}$ is leftcontinuous it follows that

$$
D_{\bar{A}}(x) \geqq D_{A}(x) .
$$

Whence $D_{\bar{A}}(x)=D_{A}(x)$ and the proof is complete.

Definition 5. Let $A$ and $B$ be nonempty subsets of $S$. The probabilistic distance between $A$ and $B$ is the function $F_{A B}$ defined by

$$
F_{A B}(x)=\operatorname{Sup}_{t<x} T\left(\operatorname{Inf}_{p \in A}\left[\operatorname{Sup}_{q \in B} F_{p q}(t)\right], \operatorname{Inf}_{q \in B}\left[\operatorname{Sup}_{p \in A} F_{p q}(t)\right]\right) .
$$

In establishing the properties of $F_{A B}$ we again omit the routine proofs.

THEOREM 12. $F_{A B}$ is a distribution function.

THEOREM 13. If $A$ and $B$ are nonempty subsets of $S$, then $F_{A B}=F_{B A}$.

Theorem 14. If $A$ is a nonempty subset of $S$, then $F_{A A}=H$.

THEOREM 15. If $A$ and $B$ are nonempty subsets of $S$, then $F_{A B}=F_{\bar{A} \bar{B}}$.

Proof. It is sufficient to show that $F_{A B}=F_{A \bar{B}}$ since this result together with Theorem 13 yields

$$
F_{A B}=F_{A \bar{B}}=F_{\bar{B} A}=F_{\bar{B} \bar{A}}=F_{\bar{A} \bar{B}} .
$$

With this in mind we first show that $F_{A \bar{B}} \leqq F_{A B}$. Since $B \subseteq \bar{B}$ for all $t$,

$$
\operatorname{Inf}_{q \in B}\left[\operatorname{Sup}_{p \in A} F_{p q}(t)\right] \geqq \operatorname{Inf}_{\bar{q} \in \bar{B}}\left[\operatorname{Sup}_{p \in A} F_{p \bar{q}}(t)\right] .
$$

Let $\eta>0$ be given. The argument given in the proof of Theorem 11 , establishes that for each point $\bar{q} \in \bar{B}$, there exists a point $q(\bar{q})$ in $B$ such that for all $t$,

$$
F_{p \bar{q}}(t-\eta)-\eta \leqq F_{p q(\bar{q})}(t) .
$$

Let $B_{\eta}=\{q(\bar{q}): \bar{q} \in \bar{B}\}$. Since $B_{\eta} \subseteq B$ we have, 


$$
\begin{aligned}
\operatorname{Sup}_{\bar{q} \in \bar{B}} F_{p \bar{q}}(t-\eta)-\eta & \leqq \operatorname{Sup}_{\bar{q} \in \bar{B}} F_{p q(\bar{q})}(t)=\operatorname{Sup}_{q \in B \eta} F_{p q}(t) \\
& \leqq \operatorname{Sup}_{q \in B} F_{p q}(t) .
\end{aligned}
$$

Consequently,

$$
\operatorname{Inf}_{p \in A}\left[\operatorname{Sup}_{\bar{q} \in \bar{B}} F_{p \bar{q}}(t-\eta)\right]-\eta \leqq \operatorname{Inf}_{p \in A}\left[\operatorname{Sup}_{q \in B} F_{p q}(t)\right] .
$$

Moreover, taking the supremum on $t<x$ of the above inequality, yields for any $\eta$,

$$
\begin{aligned}
f(x) & \stackrel{d f}{=} \operatorname{Sup}_{t<x}\left(\operatorname{Inf}_{p \in A}\left[\operatorname{Sup}_{q \in B} F_{p q}(t)\right]\right) \geqq \operatorname{Sup}_{t<x}\left(\operatorname{Inf}_{p \in A}\left[\operatorname{Sup}_{\bar{q} \in \bar{B}} F_{p \bar{q}}(t-\eta)\right]\right)-\eta \\
& =\operatorname{Sup}_{t>x-\eta}\left(\operatorname{Inf}_{q \in A}\left[\operatorname{Sup}_{\bar{q} \in \bar{B}} F_{p \bar{q}}(t)\right]\right)-\eta \stackrel{d f}{=} g(x-\eta)-\eta .
\end{aligned}
$$

Now since both $f$ and $g$ are left-continuous and $\eta$ is arbitrary, it follows that $f(x) \geqq g(x)$. This together with (2.5), and the continuity of $T$ yields

$$
\begin{aligned}
F_{A B}(x) & =T\left\{\operatorname{Sup}_{t<x}\left(\operatorname{Inf}_{p \in A}\left[\operatorname{Sup}_{q \in B} F_{p q}(t)\right]\right), \operatorname{Sup}_{t<x}\left(\operatorname{Inf}_{q \in B}\left[\operatorname{Sup}_{p \in A} F_{p q}(y)\right]\right)\right\} \\
& \geqq T\left\{\operatorname{Sup}_{t<x}\left(\operatorname{Inf}_{p \in A}\left[\operatorname{Sup}_{\bar{q} \in \bar{B}} F_{p \bar{q}}(t)\right]\right), \operatorname{Sup}_{t<x}\left(\operatorname{Inf}_{\bar{q} \in \bar{B}}\left[\operatorname{Sup}_{p \in A} F_{p \bar{q}}(t)\right]\right)\right\} \\
& =\operatorname{Sup}_{t<x} T\left(\operatorname{Inf}_{p \in A}\left[\operatorname{Sup}_{\bar{q} \in \bar{B}} F_{p \bar{q}}(t)\right], \operatorname{Inf}_{\bar{q} \in \bar{B}}\left[\operatorname{Sup}_{p \in A} F_{p \bar{q}}(t)\right]\right)=F_{A \bar{B}}(x) .
\end{aligned}
$$

A similar argument shows that $F_{A \bar{B}} \geqq F_{A B}$. Combining these inequalities yields the desired result.

THEOREM 16. If $A$ and $B$ are nonempty subsets of $S$, then $F_{A B}=H$ if and only if $\bar{A}=\bar{B}$.

Proof. Suppose $F_{A B}=H$ and let $\varepsilon>0$ be given. Then

$$
\begin{aligned}
1=F_{A B}(\varepsilon) & =T\left\{\operatorname{Sup}_{t<\varepsilon}\left(\operatorname{Inf}_{p \in A}\left[\operatorname{Sup}_{q \in B} F_{p q}(t)\right]\right), \operatorname{Sup}_{t<\varepsilon}\left(\operatorname{Inf}_{q \in B}\left[\operatorname{Sup}_{p \in A} F_{p q}(t)\right]\right)\right\} \\
& =\operatorname{Sup}_{t<\varepsilon}\left(\operatorname{Inf}_{q \in B}\left[\operatorname{Sup}_{p \in A} F_{p q}(t)\right]\right)=\operatorname{Inf}_{q \in B}\left[\operatorname{Sup}_{p \in A} F_{p q}(\varepsilon)\right] .
\end{aligned}
$$

So that for any $q \in B$ and every $\lambda>0$ there exists a point $p$ in $A$ for which $F_{p q}(\varepsilon)>1-\lambda$. Consequently, $q$ is an accumulation point of $A$ and we have $B \subseteq \bar{A}$. A similar argument shows that $A \subseteq \bar{B}$.

Conversely, suppose $\bar{A}=\bar{B}$. Then in view of Theorems 14 and 15, $F_{A B}=F_{\bar{A} \bar{B}}=F_{\bar{A} \bar{A}}=H$.

Theorem 17. If $A, B$ and $C$ are nonempty subsets of $S$, then 
for any $x$ and $y$

$$
F_{A B}(x+y) \geqq T\left(F_{A C}(x), F_{B C}(y)\right) .
$$

Proof. Let $u$ and $v$ be given. Then for any triple of points $p, q$ and $r$ in $S$ we have

$$
F_{p q}(u+v) \geqq T\left(F_{p r}(u), F_{q r}(v)\right) .
$$

Making use of the continuity and monotonicity of $T$ we have the following inequality:

$$
\operatorname{Sup}_{q \in B} F_{p q}(u+v) \geqq T\left(\operatorname{Sup}_{r \varepsilon C} F_{p r}(u), \operatorname{Inf}_{r \in C}\left[\operatorname{Sup}_{q \in B} F_{q r}(v)\right]\right) .
$$

Consequently,

$$
\operatorname{Inf}_{p \in A}\left[\operatorname{Sup}_{q \in B} F_{p q}(u+v)\right] \geqq T\left(\operatorname{Inf}_{p \in A}\left[\operatorname{Sup}_{r \in C} F_{p r}(u)\right], \operatorname{Inf}_{r \in C}\left[\operatorname{Sup}_{q \in B} F_{q r}(v)\right]\right) .
$$

Similarly,

$$
\operatorname{Inf}_{q \in B}\left[\operatorname{Sup}_{p \in A} F_{p q}(u+v)\right] \geqq T\left(\operatorname{Inf}_{r \in C}\left[\operatorname{Sup}_{p \in A} F_{p r}(u)\right], \operatorname{Inf}_{q \in B}\left[\operatorname{Sup}_{r \in C} F_{q r}(v)\right]\right) .
$$

Therefore, since $T$ is associative, we have

$$
\begin{array}{r}
T\left(\operatorname{Inf}_{p \in A}\left[\operatorname{Sup}_{q \in B} F_{p q}(u+v)\right], \operatorname{Inf}_{q \in B}\left[\operatorname{Sup}_{p \in A} F_{p q}(u+v)\right]\right) \\
\geqq T\left\{T\left(\operatorname{Inf}_{p \in A}\left[\operatorname{Sup}_{r \in C} F_{p r}(u)\right], \operatorname{Inf}_{r \in C}\left[\operatorname{Sup}_{p \in A} F_{p r}(u)\right]\right),\right. \\
\left.T\left(\operatorname{Inf}_{q \in B}\left[\operatorname{Sup}_{r \in C} F_{q r}(v)\right], \operatorname{Inf}_{r \in C}\left[\operatorname{Sup}_{q \in B} F_{q r}(v)\right]\right)\right\} .
\end{array}
$$

Now arguing as in the last step of the proof of Theorem 10, we have

$$
\begin{aligned}
& F_{A B}(x+y)=\operatorname{Sup}_{u+v<x+y} T\left(\operatorname{Inf}_{p \in A}\left[\operatorname{Sup}_{q \in B} F_{p q}(u+v)\right],\right. \\
& \left.\operatorname{Inf}_{q \in B}\left[\operatorname{Sup}_{p \in A} F_{p q}(u+v)\right]\right) \\
& \geqq \operatorname{Sup}_{u<x} T\left(\operatorname{Inf}_{p \in A}\left[\operatorname{Sup}_{q \in B} F_{p q}(u+v)\right], \operatorname{Inf}_{q \in B}\left[\operatorname{Sup}_{p \in A} F_{p q}(u+v)\right]\right) \\
& =T\left\{\operatorname{Sup}_{u<x} T\left(\operatorname{Inf}_{p \in A}\left[\operatorname{Sup}_{r \in C} F_{p r}(u)\right], \operatorname{Inf}_{r \in C}\left[\operatorname{Sup}_{p \in A} F_{p r}(u)\right]\right),\right. \\
& \left.\operatorname{Sup}_{v<y} T\left(\operatorname{Inf}_{q \in B}\left[\operatorname{Sup}_{r \in C} F_{q r}(v)\right], \operatorname{Inf}_{r \in C}\left[\operatorname{Sup}_{q \in B} F_{q r}(v)\right]\right)\right\} \\
& =T\left(F_{A C}(x), F_{B C}(y)\right) .
\end{aligned}
$$

Let $(S, \mathfrak{F}, T)$ be a Menger space under a continuous $t$-norm, $T$, and let $\mathcal{S}$ be a nonempty collection of nonempty subsets of $S$. Then 
the function $\widetilde{\mho}_{\mathbb{S}}$ defined for any $A$ and $B$ in $\subseteq$ by $\widetilde{F}_{\mathbb{S}}(A, B)=F_{A B}$, where $F_{A B}$ is given by (2.4), is a mapping from $\mathfrak{S} \times \mathfrak{S}$ into $\Delta$. Furthermore, as a direct consequence of Theorems 12-17 we have,

Theorem 18. If each set in $\mathfrak{S}$ is closed, then $\left(\mathfrak{S}, \mathfrak{F}_{\mathfrak{S}}, T\right)$ is a Menger space.

3. Quotient spaces. Let $(S, \mathfrak{F})$ be a $P M$ space. In [4] $\mathrm{K}$. Menger introduced three types of distinguishability for pairs of points $p, q$ in $S$ depending upon the behavior of the distance distribution function $F_{p q}$ near zero. These notions may be summarized in the following:

Definition 5. Let $(S, \mathfrak{F})$ be a $P M$ space, let $p$ and $q$ be points in $S$ and let $t_{p q}=\operatorname{Inf}\left\{x: F_{p q}(x)>0\right\}$. Then the distance between $p$ and $q$ is:
(A) certainly positive if $t_{p q}>0$;
(B) barely positive if $t_{p q}=0$ and $F_{p q}\left(0^{+}\right)=0$;
(C) perhaps zero if $F_{p q}\left(0^{+}\right)>0$.

In Menger's paper a somewhat different terminology was used. Namely, he said that $p$ and $q$ are: (A) certainly distinguishable if the distance between them is certainly positive; (B) barely distinguishable if the distance between them is barely positive; (C) perhaps indistinguishable if the distance between them is perhaps zero. The reasons for the slight change in the terminology introduced here will become apparent latter (see Definition 6, ff.).

The above mentioned types of distinguishability were recently reconsidered by B. Schweizer [6] who defined two relations $C$ and $D$ on $S$ as follows:

(c) $p C q$ if and only if the distance between $p$ and $q$ is perhaps zero, i.e., if and only if (C) holds.

(d) $p D q$ if and only if the distance between $p$ and $q$ is not certainly positive, i.e., if and only if either (B) or (C) holds.

Concerning these relations, he obtained the following results:

THEOREM 19. If $(S, \mathfrak{F}, T)$ is a Menger space and $T$ a t-norm such that $T(a, b)>0$ whenever $a>0$ and $b>0$, then the relation $C$ is an equivalence relation.

Theorem 20. Under the hypotheses of Theorem 19, $(S, t)$ is always a pseudo metric space. Moreover, $(S, t)$ is a metric space if and only if the distance between every pair of distinct points of $S$ is certainly positive. 
THEOREM 21. If the hypotheses of Theorem 19 are satisfied, then the relation $D$ on $S$ is an equivalence relation.

TheOREM 22. If $(S, \mathfrak{F}, T)$ is a Menger space such that

$$
\operatorname{Sup}_{a<1} T(a, a)=1
$$

and $T(a, b)>0$ whenever $a>0$ and $b>0$, then the equivalence classes in $S$ determined by the equivalence relation $D$ are closed subsets of $S$ in the $\varepsilon-\lambda$ topology.

In view of the fact that we no longer require that all the distance distribution functions have supremum one, various types of behavior at infinity are possible and can be distinguished. Indeed, the entire preceding discussion concerning behavior at zero can be dualized.

Definition 6. Let $(S, \mathfrak{F})$ be a $P M$ space, let $p$ and $q$ be points in $S$, let $s_{p q}=\operatorname{Sup}\left\{x: F_{p q}(x)<1\right\}$ and let $F_{p q}(\infty)=\lim _{x \rightarrow \infty} F_{p q}(x)$. Then the distance between $p$ and $q$ is:

$\left(\mathrm{A}^{\prime}\right)$ perhaps infinite if $F_{p q}(\infty)<1$;

(B') barely finite if $s_{p q}=\infty$ and $F_{p q}(\infty)=1$;

(C') certainly finite if $s_{p q}<\infty$.

We define two relations $C^{\prime}$ and $D^{\prime}$ on $S$ which are dual to $C$ and $D$, respectively, as follows:

$\left(c^{\prime}\right) p C^{\prime} q$ if and only if the distance between $p$ and $q$ is certainly finite, i.e., if and only if $\left(\mathrm{C}^{\prime}\right)$ holds.

(d') $p D^{\prime} q$ if and only if the distance between $p$ and $q$ is not perhaps infinite, i.e., if and only if $F_{p q}(\infty)=1$, or equivalently if and only if $\left(\mathrm{B}^{\prime}\right)$ or $\left(\mathrm{C}^{\prime}\right)$ hold.

Theorem 23. If $(S, \mathfrak{F}, T)$ is a Menger space, then $C^{\prime}$ is an equivalence relation on $S$.

Proof. The fact that $C^{\prime}$ is reflexive and symmetric is an immediate consequence of the definition of $C^{\prime}$. To show that $C^{\prime}$ is transitive suppose $p C^{\prime} q$ and $q C^{\prime} r$, so that $s_{p q}<\infty$ and $s_{q_{r}}<\infty$. Then for any $\varepsilon>0$,

$$
\begin{aligned}
F_{p r}\left(s_{p q}+s_{q_{r}}+\varepsilon\right) & \geqq T\left(F_{p q}\left(s_{p q}+\varepsilon / 2\right), F_{q r}\left(s_{q_{r}}+\varepsilon / 2\right)\right) \\
& =T(1,1)=1 .
\end{aligned}
$$

Consequently, $s_{p r} \leqq s_{p q}+s_{q r}<\infty$ and $p C^{\prime} r$.

THEOREM 24. If $(S, \mathfrak{F}, T)$ is a Menger space in which the distance between every pair of points is certainly finite, then $(S, s)$ is a metric space. 
Proof. In view of the proof of the previous theorem, we need only show that $s_{p q}=0$ implies $p=q$. To this end let $s_{p q}=0$, then $\operatorname{Sup}\left\{x: F_{p q}(x)<1\right\}=0$. Whence, $F_{p q}\left(0^{+}\right)=1$ and consequently $F_{p q}=H$ so that $p=q$.

THEOREM 25. If $(S, \mathfrak{F}, T)$ is a Menger space under a continuous $t$-norm $T$, then the relation $D^{\prime}$ on $S$ is an equivalence relation.

Proof. From $F_{p p}(\infty)=H(\infty)=1$ and $F_{p q}=F_{q_{p}}$ it follows that $D^{\prime}$ is reflexive and symmetric. To show that $D^{\prime}$ is transitive suppose $p D^{\prime} q$ and $q D^{\prime} r$. Then for any $x$,

$$
F_{p r}(x) \geqq T\left(F_{p q}(x / 2), F_{q r}(x / 2)\right) \text {. }
$$

Since $T$ is continuous the above inequality yields

$$
F_{p r}(\infty) \geqq T\left(F_{p q}(\infty), F_{q_{r}}(\infty)\right)=T(1,1)=1
$$

and thus $p D^{\prime} r$.

TheOREM 26. Let $(S, \mathfrak{F}, T)$ be a Menger space under a continuous t-norm $T$. Then the equivalence classes in $S$ determined by the equivalence relation $D^{\prime}$ are closed subsets of $S$ in the $\varepsilon-\lambda$ topology.

Proof. We first note that since $T$ is continuous on the unit square it is uniformly continuous. Now let $p \in S$ and let $D^{\prime}(p)$ be the equivalence class determined by $p$. To show that $D^{\prime}(p)$ is closed we show that $S-D^{\prime}(p)$, the complement of $D^{\prime}(p)$, is open. Let $r$ be any point in $S-D^{\prime}(p)$. Then there is a $\lambda>0$ such that $F_{p r}(\infty)=1-\lambda$. Since $T$ is uniformly continuous and since $T(a, 1)=a$, there exists an $\varepsilon>0$ such that $T(a, 1-\varepsilon)>a-\lambda / 2$ for all $a$ in $[0,1]$. Let $q \in N_{r}(\varepsilon, \varepsilon)$. Then for any $x>\varepsilon$ we have

$$
\begin{aligned}
F_{p r}(2 x) & \geqq T\left(F_{p q}(x), F_{q r}(x)\right) \geqq T\left(F_{p q}(x), 1-\varepsilon\right) \\
& >F_{p q}(x)-\lambda / 2 .
\end{aligned}
$$

Taking the limit as $x \rightarrow \infty$ yields

$$
1-\lambda=F_{p r}(\infty) \geqq F_{p q}(\infty)-\lambda / 2,
$$

whence $F_{p q}(\infty) \leqq 1-\lambda / 2$. Thus $q \notin D^{\prime}(p)$ and it follows that

$$
N_{r}(\varepsilon, \varepsilon) \subseteq S-D^{\prime}(p),
$$

hence $S-D^{\prime}(p)$ is open.

THEOREM 27. If $(S, \mathfrak{F}, T)$ is a Menger space such that $T$ is continuous and $T(a, b)>0$ whenever $a>0$ and $b>0$, then the equiva- 
lence classes in $S$ determined by $p$ and the equivalence relation $C$ are closed in the $\varepsilon-\lambda$ topology.

Proof. Let $p \in S$ and let $C(p)$ be the equivalence class determined by $p$. We show that $S-C(p)$ is open. Let $r \in S-C(p)$. Then $F_{p r}\left(0^{+}\right)=0$ so that $F_{p r}$ is continuous at 0 . Hence for every $\varepsilon>0$ there exists a $\delta>0$ such that $F_{p r}(\delta)>\varepsilon / 2$ and a $\lambda>0$ such that for all $a \in[0,1] T(a, 1-\lambda)>a-\varepsilon / 2$. Let $q \in N_{r}(\delta / 2, \lambda)$, then

$$
\begin{aligned}
\varepsilon / 2>F_{p r}(\delta) & \geqq T\left(F_{p q}(\delta / 2), F_{q r}(\delta / 2)\right) \\
& \geqq T\left(F_{p q}(\delta / 2), 1-\lambda\right)>F_{p q}(\delta / 2)-\varepsilon / 2 .
\end{aligned}
$$

Hence for every $\varepsilon>0$ there exists a $\delta>0$ such that $F_{p q}(\delta / 2)<\varepsilon$. Consequently, $F_{p q}\left(0^{+}\right)=0$. Thus $q \in S-C(p)$, whence $N_{r}(\delta / 2, \lambda) \subseteq$ $S-C(p)$ and $S-C(p)$ is open.

Theorem 28. Let $(S, \mathfrak{F}, T)$ be a Menger space under a continuous t-norm $T$. Let $p \in S$ and let $C^{\prime}(p)$ be the equivalence class in $S$ determined by $p$ and the equivalence relation $C^{\prime}$. Suppose further that there exists a number $M$ such that for any $u$ and $v$ in $C^{\prime}(p)$ we have $F_{u v}(x)=1$ whenever $x \geqq M$. Then $C^{\prime}(p)$ is closed in the $\varepsilon-\lambda$ topology.

Proof. Suppose $q$ belongs to $\overline{C^{\prime}(p)}$, the closure of $C^{\prime}(p)$, but not to $C^{\prime}(p)$. Then $F_{p q}(x)<1$ for all finite $x$, so that for any $t>0$ there is an $\varepsilon>0$ such that $F_{p q}(t+M)>1-\varepsilon$; and since $q \in \overline{C^{\prime}(p)}$, there exists a $u \in C^{\prime}(p)$ such that $F_{q u}(t)>1-\varepsilon / 2$. Whence,

$$
\begin{aligned}
1-\varepsilon & >F_{p q}(t+M) \geqq T\left(F_{p u}(M), F_{q u}(t)\right) \\
& =T\left(1, F_{q u}(t)\right)=F_{q u}(t)>1-\varepsilon / 2,
\end{aligned}
$$

which is a contradition. Thus $C^{\prime}(p)=\overline{C^{\prime}(p)}$.

The next four theorems show that, under suitable conditions, each of the equivalence relations, $C, C^{\prime}, D, D^{\prime}$, can be "divided out".

TheOREM 29. Let $(S, \mathfrak{F}, T)$ be a Menger space under a t-norm $T$ which is continuous and such that $T(a, b)>0$ whenever $a>0$ and $b>0$. For each $p \in S$, let $D(p)$ be the equivalence class in $S$ determined by $p$ and the equivalence relation $D$ and let $S / D$ be the collection of all such equivalence classes. Then $\left(S / D, \widetilde{\mho}_{S / D}, T\right)$ is a Menger space in which the distance between distinct elememts is certainly positive.

Proof. The fact that $\left(S / D, \widetilde{\mho}_{S / D}, T\right)$ is a Menger space follows directly from Theorems 18 and 22 . 
Let $D(p)$ and $D(q)$ be distinct equivalence classes, and suppose that

$$
t_{D(p) D(q)}=0 .
$$

Since $p \in D(p)$ and $q \in D(q)$, there is an $x_{0}>0$ such that $F_{p q}\left(x_{0}\right)=0$. In view of (3.2), we thus have

$$
\begin{aligned}
0 & <F_{D(p) D(q)}\left(x_{0}\right) \\
& \leqq T\left(\operatorname{Inf}_{u \in D(p)}\left[\operatorname{Sup}_{v \in D(q)} F_{u v}\left(x_{0}\right)\right], \operatorname{Inf}_{v \in D(q)}\left[\operatorname{Sup}_{u \in D(p)} F_{u v}\left(x_{0}\right)\right]\right) .
\end{aligned}
$$

Hence,

$$
0<\operatorname{Inf}_{u \in D(p)}\left[\operatorname{Sup}_{v \in D(q)} F_{u v}\left(x_{0}\right)\right],
$$

whence for each $u \in D(p)$

$$
\operatorname{Sup}_{v \in D(q)} F_{u v}\left(x_{0}\right)>0 \text {. }
$$

Consequently there exists a $q_{0} \in D(q)$ such that $F_{p q_{0}}\left(x_{0}\right)>0$. Thus since $F_{p q_{0}}$ is left-continuous, there is an $\varepsilon, 0<\varepsilon<x_{0}$, such that $F_{p q_{0}}\left(x_{0}-\varepsilon\right)>0$. Hence

$$
0=F_{p q_{0}}\left(x_{0}\right) \geqq T\left(F_{p q_{0}}\left(x_{0}-\varepsilon\right), F_{q q_{0}}(\varepsilon)\right)>0,
$$

since both $F_{p q_{0}}\left(x_{0}-\varepsilon\right)$ and $F_{q q_{0}}(\varepsilon)$ are positive. However, this is a contradiction and hence $t_{D(p) D(q)}>0$.

TheOREM 30. Let $(S, \mathfrak{F}, T)$ be a Menger space under a continuous $t$-norm T. For each $p \in S$ let $D^{\prime}(p)$ be the equivalence class in $S$ determined by $p$ and the equivalence relation $D^{\prime}$, and let $S / D^{\prime}$ be the collection of all such equivalence classes. Then $\left(S / D^{\prime}, \widetilde{\mho}_{S / D^{\prime}}, T\right)$ is a Menger space in which the distance between distinct elements is perhaps infinite.

Proof. In view of Theorems 18 and $26\left(S / D^{\prime}, \widetilde{\mho}_{S / D^{\prime}}, T\right)$ is a Menger space.

Let $D^{\prime}(p)$ and $D^{\prime}(q)$ be distinct equivalence classes and suppose that $F_{D^{\prime}(p) D^{\prime}(q)}(\infty)=1$. Since $p \in D^{\prime}(p)$ and $q \in D^{\prime}(q)$, there is an $\varepsilon>0$ such that $F_{p q}(\infty)<1-\varepsilon$. Since $T$ is continuous

$$
\begin{aligned}
1 & =F_{D^{\prime}(p) D^{\prime}(q)}(\infty) \\
& =\lim _{x \rightarrow \infty} \operatorname{Sup}_{t<x} T\left(\operatorname{Inf}_{u \in D^{\prime}(p)}\left[\operatorname{Sup}_{v \in D^{\prime}(q)} F_{u v}(t)\right], \operatorname{Inf}_{v \in D^{\prime}(q)}\left[\operatorname{Sup}_{u \in D^{\prime}(p)} F_{u v}(t)\right]\right) \\
& =\operatorname{Sup}_{t} T\left(\operatorname{Inf}_{u \in D^{\prime}(p)}\left[\operatorname{Sup}_{v \in D^{\prime}(q)} F_{u v}(t)\right], \operatorname{Inf}_{v \in D^{\prime}(q)}\left[\operatorname{Sup}_{u \in D^{\prime}(p)} F_{u v}(t)\right]\right) \\
& =T\left\{\operatorname{Sup}_{t}\left(\operatorname{Inf}_{u \in D^{\prime}(p)}\left[\operatorname{Sup}_{v \in D^{\prime}(q)} F_{u v}(t)\right]\right), \operatorname{Sup}_{t}\left(\operatorname{Inf}_{v \in D^{\prime}(q)}\left[\operatorname{Sup}_{u \in D^{\prime}(p)} F_{u v}(t)\right]\right)\right\} .
\end{aligned}
$$


But $T(a, b)=1$ if and only if $a=b=1$. Consequently,

$$
\operatorname{Sup}_{t}\left(\operatorname{Inf}_{u \in D^{\prime}(p)}\left[\operatorname{Sup}_{v \in D^{\prime}(q)} F_{u v}(t)\right]\right)=1
$$

Thus, there exists an $x_{0}$ such that

$$
\operatorname{Inf}_{u \in D^{\prime}(p)}\left[\operatorname{Sup}_{v \in D^{\prime}(q)} F_{u v}\left(x_{0}\right)\right]>1-\varepsilon / 2 .
$$

Hence,

$$
\operatorname{Sup}_{v \in D^{\prime}(q)} F_{p v}\left(x_{0}\right)>1-\varepsilon / 2
$$

Since $F_{p v}$ is nondecreasing

$$
\operatorname{Sup}_{v \in D^{\prime}(q)} F_{p v}(\infty) \geqq \operatorname{Sup}_{v \in D^{\prime}(q)} F_{p v}\left(x_{0}\right)>1-\varepsilon / 2
$$

Consequently, there exists a $q_{\mathrm{\varepsilon}} \in D^{\prime}(q)$ such that

$$
F_{p q}(\infty)<\operatorname{Sup}_{v \in D^{\prime}(q)} F_{p v}(\infty)-\varepsilon / 4>1-3 \varepsilon / 4
$$

and we have

$$
1-\varepsilon>F_{p q}(\infty) \geqq T\left(F_{p q_{\varepsilon}}(\infty), F_{q q_{\varepsilon}}(\infty)\right)=F_{p q_{\varepsilon}}(\infty)>1-3 \varepsilon / 4 .
$$

which is a contradiction. Hence $F_{D^{\prime}(p) D^{\prime}(q)}(\infty)<1$ and the distance between distinct equivalence classes is perpaps infinite.

THEOREM 31. Let $(S, \mathfrak{F}, T)$ be a Menger space under a t-norm $T$ which is continuous and such that $T(a, b)>0$ whenever $a>0$ and $b>0$. For each $p \in S$, let $C(p)$ be the equivalence class in $S$ determined by $p$ and the equivalence relation $C$, and let $S / C$ be the collection of all such equivalence classes. Then $\left(S / C, \mho_{s / C}, T\right)$ is a Menger space. Moreover, if each $C(p)$ in $S / C$ is such that $\operatorname{Inf}_{u, v \in C(p)} F_{u v}\left(0^{+}\right)>0$, then the distance between distinct elements is not perhaps zero.

Proof. The first part of this theorem is a direct consequence of Theorems 18 and 27.

To establish the second part, let $C(p)$ and $C(q)$ be distinct equivalence classes, and suppose that $F_{C(p) C(q)}\left(0^{+}\right)>0$. Since $p \in C(p)$ and $q \in C(q)$, we note first that

$$
F_{p q}\left(0^{+}\right)=0 \text {. }
$$

Next we have 


$$
\begin{aligned}
0 & <F_{C(p) C(q)}\left(0^{+}\right) \\
& \left.=\lim _{h \rightarrow 0+t<h} \operatorname{Sup}_{\left(\operatorname{Inf}_{u \in C(p)}\right.}\left[\operatorname{Sup}_{v \in C(q)} F_{u v}(t)\right], \operatorname{Inf}_{v \in C(q)}\left[\operatorname{Sup}_{u \in C(p)} F_{u v}(t)\right]\right) \\
& \leqq \lim _{h \rightarrow 0^{+}} T\left(\operatorname{Inf}_{u \in C(p)}\left[\operatorname{Sup}_{v \in C(q)} F_{u v}(h)\right], \operatorname{Inf}_{v \in C(q)}\left[\operatorname{Sup}_{u \in C(p)} F_{u v}(h)\right]\right) \\
& =T\left(\lim _{h \rightarrow 0^{+}} \operatorname{Inf}_{u \in C(p)}\left[\operatorname{Sup}_{v \in C(q)} F_{u v}(h)\right], \lim _{h \rightarrow 0^{+}} \operatorname{Inf}_{v \in C(q)}\left[\operatorname{Sup}_{u \in C(p)} F_{u v}(h)\right]\right),
\end{aligned}
$$

whence

$$
\lim _{h \rightarrow 0^{+}}\left(\operatorname{Inf}_{u \in C(p)}\left[\operatorname{Sup}_{v \in C(q)} F_{u v}(h)\right]\right)=\lambda>0 .
$$

Thus, in particular,

$$
\lim _{h \rightarrow 0^{+}}\left(\operatorname{Sup}_{v \in O(q)} F_{p v}(h)\right) \geqq \lambda>\lambda / 2>0 .
$$

Since $\operatorname{Sup}_{v \in C(q)} F_{p v}$ is increasing, for any $h>0$ we have,

$$
\operatorname{Sup}_{v \in C(\boldsymbol{g})} F_{p v}(h)>\lambda / 2 \text {. }
$$

From (3.4) it follows that for each $h>0$ there exists a $q_{h} \in C(q)$ such that

$$
F_{p q_{h}}(h)>\lambda / 2 \text {. }
$$

Now let $\operatorname{Inf}_{u, v \in C(q)} F_{u v}\left(0^{+}\right)=\eta$. By hypothesis, $\eta>0$, whence

$$
T(\lambda / 2, \eta)>0 \text {. }
$$

Moreover, since $q_{h} \in C(q)$

$$
F_{q q_{h}}(h) \geqq \eta,
$$

for all $h>0$. Next, in view of (3.3), there exists an $h_{0}>0$ such that

$$
F_{p q}\left(2 h_{0}\right)<T(\lambda / 2, \eta) \text {. }
$$

Combining the inequalities (3.5), (3.6) and (3.7) we have

$$
T(\lambda / 2, \eta)>F_{p q}\left(2 h_{0}\right) \geqq T\left({ }_{p q_{h_{0}}}\left(h_{0}\right), F_{q q_{h_{0}}}\left(h_{0}\right)\right) \geqq T(\lambda / 2, \eta),
$$

which is a contradiction. Hence $F_{C(p) C(q)}\left(0^{+}\right)=0$ and the proof is complete.

THEOREM 32. Let $(S, \mathfrak{F}, T)$ be a Menger space under a continuous t-norm $T$. For each $p \in S$ let $C^{\prime}(p)$ be the equivalence class in $S$ determined by $p$ and the equivalence relation $C^{\prime}$, and let $S / C^{\prime}$ be the collection of all such equivalence classes. If each $C^{\prime}(p)$ in $S / C^{\prime}$ is 
such that for some $M_{p}, s_{u v}<M_{p}$ for all $u$ and $v$ in $C^{\prime}(p)$, then $\left(S / C^{\prime}, \widetilde{\mho}_{s / C^{\prime}}, T\right)$ is a Menger space in which the distance between distinct elements is not certainly finite.

Proof. In view of Theorems 18 and $28\left(S / C^{\prime}, \widetilde{\mho}_{S / C^{\prime}}, T\right)$ is a Menger space.

Let $C^{\prime}(p)$ and $C^{\prime}(q)$ be distinct equivalence classes and suppose that

$$
s_{C^{\prime}(p) C^{\prime}(q)}<\infty .
$$

Since $p \in C^{\prime}(p)$ and $q \in C^{\prime}(q)$ for each $\lambda>0$ there is an $\varepsilon>0$ such that

$$
F_{p q}\left(s_{C^{\prime}(p) C^{\prime}(q)}+M_{q}+\lambda\right)<1-\varepsilon,
$$

where $s_{u v}<M_{q}$ for all $u$ and $v$ in $C^{\prime}(q)$. In view of (3.8),

$$
\begin{gathered}
1=F_{C^{\prime}(p) C^{\prime}(q)}\left(s_{C^{\prime}(p) C^{\prime}(q)}+\lambda / 2\right) \\
=\operatorname{Sup}_{t<s_{C^{\prime}(p) O^{\prime}(q)+\lambda / 2}} T\left(\operatorname{Inf}_{u \in C^{\prime}(p)}\left[\operatorname{Sup}_{v \in C^{\prime}(q)} F_{u v}(t)\right],\right. \\
\left.\operatorname{Inf}_{v \in C^{\prime}(q)}\left[\operatorname{Sup}_{u \in C^{\prime}(p)} F_{u v}(t)\right]\right) \\
=T\left(\operatorname{Inf}_{u \in C^{\prime}(p)}\left[\operatorname{Sup}_{v \in C^{\prime}(q)} F_{u v}\left(s_{C^{\prime}(p) C^{\prime}(q)}+\lambda / 2\right)\right],\right. \\
\left.\operatorname{Inf}_{v \in C^{\prime}(q)}\left[\operatorname{Sup}_{u \in C^{\prime}(p)} F_{u v}\left(s_{C^{\prime}(p) C^{\prime}(q)}+\lambda / 2\right)\right]\right) .
\end{gathered}
$$

Since $T(a, b)=1$ if and only if $a=b=1$, it follows that

$$
\operatorname{Inf}_{u \in C^{\prime}(p)}\left[\operatorname{Sup}_{v \in C^{\prime}(q)} F_{u v}\left(s_{C^{\prime}(p) C^{\prime}(q)}+\lambda / 2\right)\right]=1,
$$

whence, in particular,

$$
\operatorname{Sup}_{v \in C^{\prime}(q)} F_{p v}\left(s_{C^{\prime}(p) C^{\prime}(q)}+\lambda / 2\right)=1 .
$$

Thus, there exists a $q_{\varepsilon} \in C^{\prime}(q)$ such that

$$
F_{p q_{\varepsilon}}\left(s_{C^{\prime}(p) C^{\prime}(q)}+\lambda / 2\right)>1-\varepsilon / 2 .
$$

Combining (3.9) and (3.10), we have

$$
\begin{aligned}
1-\varepsilon & >F_{p q}\left(s_{C^{\prime}(p) C^{\prime}(q)}+M_{q}+\lambda\right) \\
& \geqq T\left(F_{p q_{\varepsilon}}\left(s_{C^{\prime}(p) C^{\prime}(q)}+\lambda / 2\right), F_{q q_{\varepsilon}}\left(M_{q}+\lambda / 2\right)\right) \\
& =T\left(F_{p q_{\varepsilon}}\left(s_{C^{\prime}(p) C^{\prime}(q)}+\lambda / 2\right), 1\right) \\
& =F_{p q_{\varepsilon}}\left(s_{C^{\prime}(p) C^{\prime}(q)}+\lambda / 2\right)>1-\varepsilon / 2 .
\end{aligned}
$$

This is a contradiction, whence $s_{C^{\prime}(p) C^{\prime}(q)}=\infty$ and the proof is complete. In conclusion we note that under the hypotheses of Theorem 31 
the equivalence classes in $S / C$ are either bounded or semi-bounded and under the hypotheses of Theorem 32 the equivalence classes in $S / C^{\prime}$ are bounded.

\section{REFERENCES}

1. R. Egbert, Cartesian products of statistical metric spaces, Amer. Math. Soc. Notices 10 (1963), 266-267.

2. V. Istratescu and I. Vaduva, Products of statistical metric spaces (Romanian), Acad. R. P. Romine Stud. Cerc. Mat. 12 (1961), 567-574.

3. K. Menger, Statistical metrics, Proc. Nat. Acad. of Sci. U.S.A. 28 (1942), 535-537. 4. — Probabilistic geometry, Pro. Nat. Acad. of Sci. U.S.A. 37 (1951), 226-229. 5. - Géométrie générale (Chap. VII), Mémorial des Sciences Mathematiques, No. 124, Paris 1954.

6. B. Schweizer, Equivalence relations in probabilistic metric spaces, Bulletin of the Polytechnic Inst. of Jassy 10 (1964), 67-70.

7. L Lectures on probabilistic metric spaces, lecture notes, The University of Arizona (1965), unpubl.

8. - On the uniform continuity of the probabilistic distance, $\mathrm{Z}$. Wahrcheinlichkeitstheorie verw. Geb. 5 (1966) 357-360.

9. B. Schweizer and A. Sklar, Espaces métriques aléatoires, C. R. Acad. Sci., Paris 247 (1958), 2092-2094.

10. B. Schweizer and A. Sklar, Statistical metric spaces, Pacific J. Math. 10 (1960), 314-334.

11. - Associative functions and statistical triangle inequalities, Publicationes Mathematicae, Debrecen 8 (1961), 169-186.

12. - Triangle inequalities in a class of statistical metric spaces, J. London Math. Soc. 38 (1963), 401-406.

13. B. Schweizer, A. Sklar and E. Thorp, The metrization of statistical metric svaces, Pacific J. Math. 10 (1960), 673-675.

14. A. N. Serstnev, On the concept of a random normed space, (Russian), Dokl. Akad. Nauk SSSR 149 (1963) 280-283.

15. E. Thorp, Generalized topologies for statistical metric spaces, Fundamenta Mathematicae 51 (1962), 9-21.

16. A. Wald, On a statistical generalization of metric spaces, Proc. Nat. Acad. of Sci. U.S.A. 29 (1943), 196-197.

17. A. F. S. Xavier, On the product of probabilistic metric spaces, Universidade Federal Do Ceara Instituto De Mathematica, (1965), unpub.

\section{BRIGHAM YOUNG UNIVERSITY}

Provo, UTAH

Received February 15, 1966. The results are from the author's Ph. D. dissertation, written at the University of Arizona and directed by Professor B. Schweizer. The support of the National Science Foundation through NSF grants G-19825 and GP-163 is gratefully acknowleged. 



\section{PACIFIC JOURNAL OF MATHEMATICS}

\section{EDITORS}

\author{
H. ROYDEN \\ Stanford University \\ Stanford, California
}

\author{
J. P. JANS \\ University of Washington \\ Seattle, Washington 98105
}

J. DugundJI

Department of Mathematics

Rice University

Houston, Texas 77001

RICHARD ARENS

University of California

Los Angeles, California 90024

\section{ASSOCIATE EDITORS}
E. F. BECKENBACH
B. H. NeumanN
F. WOLF
K. YOSIDA

\section{SUPPORTING INSTITUTIONS}

\author{
UNIVERSITY OF BRITISH COLUMBIA \\ CALIFORNIA INSTITUTE OF TECHNOLOGY \\ UNIVERSITY OF CALIFORNIA \\ MONTANA STATE UNIVERSITY \\ UNIVERSITY OF NEVADA \\ NEW MEXICO STATE UNIVERSITY \\ OREGON STATE UNIVERSITY \\ UNIVERSITY OF OREGON \\ OSAKA UNIVERSITY \\ UNIVERSITY OF SOUTHERN CALIFORNIA
}

\author{
STANFORD UNIVERSITY \\ UNIVERSITY OF TOKYO \\ UNIVERSITY OF UTAH \\ WASHINGTON STATE UNIVERSITY \\ UNIVERSITY OF WASHINGTON \\ AMERICAN MATHEMATICAL SOCIETY \\ CHEVRON RESEARCH CORPORATION \\ TRW SYSTEMS \\ NAVAL ORDNANCE TEST STATION
}

\footnotetext{
Mathematical papers intended for publication in the Pacific Journal of Mathematics should be in typed form or offset-reproduced, double spaced with large margins. Underline Greek letters in red, German in green, and script in blue. The first paragraph or two must be capable of being used separately as a synopsis of the entire paper. It should not contain references to the bibliography. Manuscripts may be sent to any one of the four editors. All other communications to the editors should be addressed to the managing editor, Richard Arens, University of California, Los Angeles, California 90024.

Each author of each article receives 50 reprints free of charge; additional copies may be obtained at cost in multiples of 50 .

The Pacific Journal of Mathematics is published monthly. Effective with Volume 16 the price per volume (3 numbers) is $\$ 8.00$; single issues, $\$ 3.00$. Special price for current issues to individual faculty members of supporting institutions and to individual members of the American Mathematical Society: $\$ 4.00$ per volume; single issues $\$ 1.50$. Back numbers are available.

Subscriptions, orders for back numbers, and changes of address should be sent to Pacific Journal of Mathematics, 103 Highland Boulevard, Berkeley 8, California.

Printed at Kokusai Bunken Insatsusha (International Academic Printing Co., Ltd.), 7-17, Fujimi 2-chome, Chiyoda-ku, Tokyo, Japan.

PUBLISHED BY PACIFIC JOURNAL OF MATHEMATICS, A NON-PROFIT CORPORATION

The Supporting Institutions listed above contribute to the cost of publication of this Journal, but they are not owners of publishers and have no responsibility for its content or policies.
} 


\section{Pacific Journal of Mathematics}

\section{Vol. 24, No. $3 \quad$ July, 1968}

Duane W. Bailey, On symmetry in certain group algebras ............ 413

Lawrence Peter Belluce and Surender Kumar Jain, Prime rings with a one-sided ideal satisfying a polynomial identity ................ 421

L. Carlitz, A note on certain biorthogonal polynomials ............. 425

Charles O. Christenson and Richard Paul Osborne, Pointlike subsets of a manifold ......................................... 431

Russell James Egbert, Products and quotients of probabilistic metric

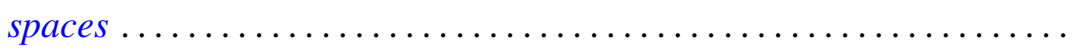

Moses Glasner, Richard Emanuel Katz and Mitsuru Nakai, Bisection into small annuli ..................................... 457

Karl Edwin Gustafson, A note on left multiplication of semigroup

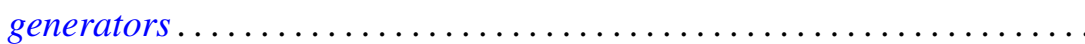

I. Martin (Irving) Isaacs and Donald Steven Passman, A characterization of groups in terms of the degrees of their characters. II ............. 467

Howard Wilson Lambert and Richard Benjamin Sher, Point-like

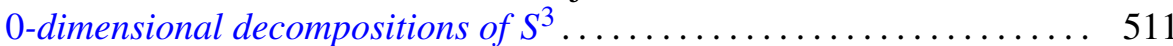

Oscar Tivis Nelson, Subdirect decompositions of lattices of width two ..... 519

Ralph Tyrrell Rockafellar, Integrals which are convex functionals . . . . . . . 525

James McLean Sloss, Reflection laws of systems of second order elliptic differential equations in two independent variables with constant coefficients ...

Bui An Ton, Nonlinear elliptic convolution equations of Wiener-Hopf type in a bounded region

Daniel Eliot Wulbert, Some complemented function spaces in $C(X)$

Zvi Ziegler, On the characterization of measures of the cone dual to a generalized convexity cone. 